\title{
¿La voz de los sin voz? Análisis crítico de la producción e interpretación de testimonios en las ciencias sociales ${ }^{1}$
}

JoRGE IVÁN VERGARA DEL $S .^{2}$

\section{RESUMEN}

El artículo analiza las condiciones de validez del testimonio en ciencias sociales. Sus potencialidades centrales son el constituir un campo de exploración e investigación de acercamiento a la subjetividad, especialmente a la de los sectores populares. Ello ha permitido incorporar sus discursos y representaciones en las ciencias sociales. Sin embargo, dicha incorporación se ha realizado bajo una perspectiva empirista, según la cual el testimonio es una representación inmediata, directa de los sujetos, lo que oculta la mediación del testimonio a través del cientista social, particularmente mediante la entrevista. Por ende, la idea del testimonio como una "voz de los sin voz" oculta el diálogo entre investigador-sujetos, que podría ser potenciado en un tipo de investigación hermeneútica en la que el investigador ya no ostentaría el monopolio de la interpretación.

\footnotetext{
ABSTRACT

This article analises the validity conditions of "testimony" as a methodological tool in the social sciences. The principal advantage of testimony is that it enables the construction of research and nal realizada en el Primer Congreso de Antropología y Mujer, llevado a cabo en Santiago de Chile entre los días 9 y 11 de mayo de 1990 y organizado por la Comisión de la Mujer del Colegio de Antropólogos de Chile

2 Departamento de Ciencias Sociales de la Universidad Arturo Prat, Iquique, jovergara@cec.unap.cl
}

analysis of subjectivity, particularly with popular sectors. This has facilitated the incorporation of their discourses and representations into the social sciences. Notwithstanding, this incorporation has occurred within a highly empiricist perspective, whereby testimony is an immediate representation of the individual. The mediation of the social scientist, which is particularly significant in interviews, remains hidden. The concept of testimony, therefore, as the "voice of the voiceless" disguises the dialogue between the researcher and the individual. This dialogue could be further developed as an instrument of hermeneutical research, whereby the researcher no longer monopolises interpretations.

\section{Introducción}

Desde los años ochenta en las ciencias sociales latinoamericanas se ha producido un creciente interés en el uso de los relatos e historias de vida, autobiografías y testimonios. Este desarrollo se ha expresado fundamentalmente en la producción de trabajos de investigación basados en este tipo de metodologías, en muchos casos de relatos autobiográficos de personas provenientes de los sectores subalternos. Paralelamente, ha ido emergiendo también un debate teórico y metodológico acerca de las posibilidades y límites de estas formas de investigación. ${ }^{3}$ En este artículo nos interesa contribuir a dicho debate desde una perspectiva crítica. zadas por Jorge Balán (1974) y V. Hugo Acuña (1980), 
Al hablar de crítica, lo hacemos en el sentido original que tiene en Kant. Para Kant, la crítica de la razón significa superar tanto el dogmatismo ingenuo como el de los escépticos. Supone la doble superación de ambas posiciones. A la vez, se trata de mostrar las potencialidades y los límites de la razón. En este caso se busca cuestionar una concepción empirista del testimonio, así como una visión escéptica que le niega todo valor y mostrar también las limitaciones de esta forma de conocimiento de la realidad social. ${ }^{4} \mathrm{~A}$ un nivel teóricometodológico más general, se trataría de contribuir a superar la dicotomía entre subjetivismoobjetivismo en la teoría social.

La crítica propuesta intenta ser además una crítica inmanente, o sea, que "emplea ... los instrumentos conceptuales de su objeto" (Marcuse, 1958: 7); en este caso, parte de los propios supuestos de quienes defienden el uso de testimonios, mostrando que son contradichos por las formas de trabajo empleadas en este tipo de estudios.

En la primera parte del trabajo intentaremos exponer aquellos elementos, a nuestro juicio, más aportadores y renovadores del testimonio, poniéndolos en relación con las transformaciones que han posibilitado el surgimiento de un mayor interés por su uso en la investigación social. Aquí haremos especial referencia al caso de los estudios de mujeres populares en Chile.

En la segunda parte, en cambio, nos interesará ejercer un análisis crítico en el sentido recién expuesto. Al respecto se analizarán las principales con- diciones de producción del testimonio en ciencias sociales para mostrar la presencia del investigador como un coautor del testimonio y no sólo como un recolector de aquél. De esta forma, cuestionaremos la idea empirista del testimonio como una representación inmediata de las significaciones, modos de concebir el mundo y la experiencia, de los sujetos, particularmente de los sectores subalternos. Lo haremos desde la perspectiva de las ciencias sociales, sin poder considerar aquí otras disciplinas, como la teoría y la crítica literarias, donde ha habido un debate muy importante sobre el llamado "género testimonial", o, simplemente, el "testimonio". Cabe al menos señalar la centralidad que adquirió en ella el problema de la representación, sobre todo de los dominados. Se planteó un cuestionamiento de lo que, según veremos, constituye uno de los supuestos centrales de los autores y defensores de la literatura testimonial: la pretensión de ser una expresión no mediada de los sujetos.

En este debate puede constatarse una gran influencia de concepciones de corte postmoderno y postestructuralista, aunque también aparecen otras posiciones teóricas y filosóficas más tradicionales, como el marxismo. ${ }^{5}$ Por ende, se han tratado no sólo cuestiones relativas a la producción literaria latinoamericana, sino que también problemas teóricos generales, como el de la representación de la subalternidad, que emergió con gran fuerza con los trabajos de Spivak y de Babha sobre el discurso postcolonial. ${ }^{6}$ Sería de gran interés examinar la importancia de estas posiciones y argumentos en juego en este debate sobre el testi- donde se incluyen fundamentalmente trabajos de cientistas sociales europeos y norteamericanos. Respecto a Chile, cabe mencionar el número 29 de la revista Proposiciones, publicado en 1999 y dedicado a "historias y relatos de vida". En él se han incluido trabajos de autores extranjeros y nacionales. Hasta donde sabemos. se trata de la única publicación reciente dedicada al tema en nuestro país. También son de mucho interés los trabajos editados por J.A. Bravo (1987) y Jorge Nárvaez (1988).

4 De manera similar, Giddens (1976: 10) habla de una "crítica positiva" de las sociologías interpretativas, que "es una crítica 'simpatética' o 'constructiva".

5 Véase especialmente los artículos publicados en el libro editado por Beverley y Achugar (1992), La voz del otro.
En español, puede consultarse la compilación de trabajos sobre la subalternidad hecha por Silvia Rivera y Rossana Barragán (1997), donde se incluyen contribuciones de R. Guha, G. Pandey. S. Amin, P. Catterjee, D. Chakrabarty, G. Spivak, V. Daas y G. Prakash. Para una visión muy receptiva de las categorías de Bhaba en relación a América Latina, véase: Rincón (1994). Se deben considerar también las críticas realizadas a estos autores dentro del debate contemporáneo. Destaco aquí la crítica de Ahmed (1995) a Spivak y Bhaba respecto a la "postcolonialidad", así como de Kanefsky (1996) a la idea postmodernista de la historia como mera construcción narrativa. Lejos de suponer una recuperación de las visiones marginales sobre la historia, ésta significaría una "deslegitimación de todas las voces", at relativizar la verdad histórica, desarticulando además el sentido de 
monio. ${ }^{7}$ Sin embargo, esto excedería en mucho el marco de un artículo y nuestra competencia académica.

Nos proponemos, en cambio, un objetivo más modesto, pero que consideramos puede representar un aporte a esta discusión, la cuestión metodológica de la producción de los testimonios dentro del ámbito de las ciencias sociales. ${ }^{8}$ Consideramos ésto pertinente por dos razones. La primera es que significa colocar en el debate el proceso de creación del testimonio, más que el resultado, el texto mismo, como se ha hecho hasta ahora. Así, proponemos un énfasis más metodológico que narrativo.

Asimismo, esta discusión sobre el testimonio no ha considerado suficientemente la importancia creciente de los cientistas sociales en la elaboración de libros y trabajos donde se reproducen y, en algunos casos, también se interpretan testimonios de diversos sujetos sociales. Por ello, nuestro análisis se limitará a las ciencias sociales y no pretende tener validez más allá de éstas. No obstante, nos ha parecido pertinente indicar al menos algunas coincidencias respecto de algunos estudios de crítica literaria, e incluso hemos tomado algunas ideas centrales de una destacada representante de esta disciplina, Jean Franco (1988). No ignoramos que, en el caso del testimonio, las fronteras entre literatura y ciencias sociales son muy tenues, aunque no inexistentes. En cualquier caso, conside- ramos este tipo de indagación complementaria de aquellas que se llevan a cabo en la teoría y la crítica literarias, sin mencionar la crítica cultural.

Una última delimitación es geográfica y temática. Nos centraremos en el caso de Chile, sobre el cual disponemos de un material más o menos completo, $y$ en los testimonios de mujeres populares, no sólo porque representaron una de las preocupaciones fundamentales de los estudios de este tipo, sino también porque en ellos se pone de manifiesto un problema más amplio, cual es el de la representación de los dominados en las ciencias sociales. Por ende, en términos generales, lo dicho respecto a los testimonios de mujeres en Chile tiene validez para otros casos, como el de los indígenas, los campesinos, los obreros, entre otros. Los testimonios de mujeres consideran en alguna medida estas formas de subalternidad, en la medida en que la dimensión de género siempre está sobredeterminada por otras dimensiones: de clase, de estatus social, etárea, y otros. ${ }^{9}$

\section{Testimonio: Las razones de un rescate y sus potencialidades}

Según dijimos, desde los años ochenta los testimonios han sido utilizados como un recurso habitual en las ciencias sociales en Chile y en otros países de Latinoamérica. Aunque los estudios han abarcado una gran diversidad de temáticas, existen ciertas problemáticas recurrentes. Una de ellas comunidad en los grupos minoritarios, que no estaría ligado exclusivamente a, o sería impuesto necesariamente por un centro dominante.

7 Al respecto, puede consultarse Beverley (1992).

8 Al decir metodología me refiero no a las técnicas de investigación y contrastación empíricas, como se entiende habitualmente, sino a las condiciones de producción del objeto de estudio, que, como han señalado Adorno (1957), Giddens (1976), Marx (1857/1858) y otros críticos del empirismo sociológico, no es un objeto dado en la realidad sino construido por el investigador

9 Al respecto, hay una vastísima bibliografía. El punto está bien subrayado por Montecino (1996: 32): "las relaciones de género estarían también signadas por la clase, la etnia, la edad y el contexto social e histórico donde se anidan". En este mismo sentido, Toledo
(1993: 54-55) hace una interesante crítica a la reducción de las mujeres a una "identidad sustantiva", separada de otras identidades: "sus identidades se restringen a una sola, la de género y esta queda referida a un universal, no a una construcción simbólica y social, histórica". Menos interesante me parece la propuesta de ambos autores de referir esta multiplicidad y diversidad de identidades a "nuestra condición mestiza y colonizada" (Montecino, 1996: 33), o de un "mestizaje de las disciplinas" acorde con el "mestizaje de las culturas" (Toledo, 1993: 60). En el primer caso, la multiplicidad reconocida originalmente queda de alguna manera negada por la doble determinación "mestiza" y "colonial"; en el segundo se pretende, de manera empirista, poner en un mismo plano distintas disciplinas, tcorías y conceptos. 
ha sido la situación de la mujer, ya se trate de la mujer pobladora, ${ }^{10}$ de la mujer campesina, ${ }^{11}$ o bien de la mujer mapuche. ${ }^{12}$ También se ha dedicado atención preferente al tema de la cultura y/o visión de mundo campesina. ${ }^{13}$

Algunas de las formas de presentación y de análisis de los relatos seguían las empleadas tradicionalmente en las monografías antropológicas y sociológicas. Otras, en cambio, se apegaron menos a esas normas y sufrieron un mayor o menor rechazo de parte de muchos investigadores. ${ }^{14}$ Hasta donde sabemos, las razones de este rechazo no han sido expuestas en forma sistemática, lo cual le resta valor. ${ }^{15}$ Sin embargo, consideramos que la crítica a esta perspectiva de investigación es un requisito indispensable para evaluar las potencialidades de la producción y uso de testimonios en ciencias sociales. El presente trabajo intenta contribuir a esta labor y esbozar una posible alternativa a las dificultades planteadas.

Creemos que hay tres factores que permiten explicar la revalorización del testimonio en las ciencias sociales, en especial, del testimonio de mujeres populares.

En primer lugar, en las ciencias sociales se ha producido un resurgimiento de modalidades de investigación cualitativas como las historias de vida, historia oral, entre otras, que habían sido desplazadas a un lugar secundario por el desarrollo de las técnicas de medición cuantitativa y el predominio de una concepción positivista de aquellas (Bértaux, 1980; Piña, 1986). Los relatos de vida, por ejemplo, sufrieron a partir de los años treinta del siglo pasado una serie de críticas que cuestionaban su utilidad científica. Especial relevancia adquirieron los planteamientos de Samuel Stouffer, uno de los mayores promotores del uso del método de encuesta (survey research). Stouffer consideraba a este método muy superior a los relatos de vida ya que permitían "obtener la misma información específica...pero a un costo mucho menor" (Bértaux, 1980: 60). ${ }^{16}$ Fue en esta misma época que se produjo una modificación del sentido del término "encuesta". Hasta entonces, se había llamado "encuesta social" al estudio en terreno de las condiciones de vida de determinados grupos sociales, en especial de sectores populares urbanos. Estos estudios "revelaban y describían costumbres e instituciones tanto como opiniones" (Hughes, 1960: 11). Con la creación de "métodos cuantitativos más eficaces de elaboración de los datos sociales" pasó a llamarse "encuesta" al "estudio de las opiniones políticas o de otro carácter, entre ellas las preferencias de los consumidores, mediante entrevistas, con preguntas previamente establecidas e individuos elegidos con métodos estadísticos" (Ibid: 12).
Raczynski y Serrano (1985), Valdés, T. (1988), Guerra y Skewes (1999).

11 De León, (1986), Valdés y Matta (1986), Valdés, X. et al. (1983) y Valdés, X. (1988)

12 Guerra et al (1999), Lorca y Pinda (2000), Montecino (1982, 1984 y 1985); Montecino, Rebolledo y Wilson (1993), Weyer (1998).

13 Acuña (1986) y Canales (1988)

14 Ha sido el caso de la historia oral, que no ha sido aceptada ni incorporada por muchos historiadores que cuestionan el uso de fuentes orales, supuestamente teñidas de subjetividad y sostenidas en el recurso frágil de la memoria. Para citar un ejemplo chileno, véase las críticas de Villalobos (1993: 557-558) a Historia del Pueblo Mapuche de José Bengoa (1985), por la incorporación de "declaraciones orales" que "carecen de objetividad" y habrían sido además mal utilizadas metodológicamente.

15 Esto se refiere exclusivamente a las ciencias sociales, no a la crítica literaria, donde, como dijimos, sí ha habido una discusión teórica y metodológica respecto al testimonio.

16 Es importante considerar aquí el contexto histórico.

\begin{abstract}
Stouffer formó parte del Bureau of Applied Research de la Universidad de Columbia, en el que participaron también Robert K. Merton y Paul Lazarsfeld, y cuyo desarrollo se debió en buena medida a la Segunda Guerra Mundial, período en el cual se le encargaron muchos proyectos del Ministerio de Guerra. El más importante y conocido fue The American Soldier, cuatro vólumenes editados por Stouffer entre 1949 y 1950 (Pollock, 1979: 55 y 61). Esto llevó a una confrontación con la Escuela de Chicago, decidida partidaria de la etnografía y las historias de vida. Según Pollock, "En esta batalla a la búsqueda de la legitimidad científica la sociografía de la Escuela de Chicago padecía varias desventajas si se la compara a la sociología de sondeos, la survey research: en la medida en que dicha Escuela recurría a técnicas de observación con frecuencia "cualitativas" se le reprochaba que ilustraba más que probaba, que describía, mientras que las técnicas cuantitativas pretendían poder predecir. En nombre de la eficacia, de la utilidad y de la cientificidad (gracias a la cuantificación y la matematización) la ventaja recaía finalmente sobre la nueva Escuela de Columbia" (Ibid: 61).
\end{abstract}


La crisis de los enfoques y métodos objetivistas en las ciencias sociales ha implicado, pues, un fenómeno de recuperación de éstas y otras técnicas de investigación similares, aunque la forma en que se utilizan hoy, las perspectivas teóricas y epistemológicas, así como los tipos de análisis, entre otros aspectos, se han modificado desde entonces. Se admite, por ejemplo, que "la historia oral es tan antigua como la historia misma" (Thompson, 1978: 19). Sin embargo, las características que asume hoy en día la historia oral son el resultado de desarrollos recientes. Como se recordará, las experiencias pioneras en este campo comenzaron en los Estados Unidos, cuando Allan Nevins estableció la Oficina de Investigación Oral en la Universidad de Columbia en 1948, en el mismo período de predominio de los enfoques positivistas dentro de dicha institución y, en general, dentro de los centros académicos norteamericanos (Nevins, 1966; Hoffman, 1974: 68). A los esfuerzos de Nevins y de su equipo se sumaron, un poco más tarde, los de antropólogos e historiadores africanistas, entre los cuales destacó Jan Vansina, autor de importantes trabajos sobre la materia (Vansina, 1967 y 1985). El crecimiento explosivo y la propagación mundial de la historia oral comenzaron recién en los años sesenta (Starr, 1977). En el caso de América Latina, su desarrollo ha sido más tardío que en los países del Norte, iniciándose recién en la década de 1970 (Schwarzstein, 1995).

En segundo lugar, este interés por los testimonios, autobiografías, etc., no ha sido causado sólo por las transformaciones de las ciencias sociales. Las condiciones políticas, sociales y económicas del mundo contemporáneo han tenido también una influencia decisiva. Esto puede resultar más o menos evidente en el caso de Chile y de otros países latinoamericanos afectados por profundas transformaciones desde la implantación de regímenes autoritarios a comienzos de los años setenta. La necesidad de conocer tales cambios condujo a muchos cientistas sociales de la región a buscar "métodos de análisis que superen los límites de las sociologías exclusivamente estructurales y objetivistas y que reconocieran la relevancia de la dimensión subjetiva de lo social" (Vergara, 1995: 45). Se despertó también un interés por la vida cotidiana, afectada drásticamente por los cambios ya mencionados.
Sin embargo, de ello no se sigue inmediatamente una mayor preocupación por los problemas y perspectivas de un determinado sujeto social, como es el caso de las mujeres campesinas chilenas. Escribe Ximena Valdés, (1988:12-13) "es difícil encontrar una página, una frase dedicada a las mujeres en los numerosos estudios hechos en la década de los sesenta y comienzos de los setenta". Agrega que "durante los años que conmovieron al campo y a la sociedad chilena, que corresponden al período de la Reforma Agraria, hubo proliferaciones de estudios acerca de los trabajadores del campo. Sin embargo, las mujeres no fueron en este momento foco de interés" (Ibid: 13). Durante el período de reforma neoliberal en el agro sí existió una preocupación por conocer la situación de la mujer campesina. Se estudió, por ejemplo, su contribución a la economía campesina (Campaña, 1982 y 1985, entre otros). Resulta obvio que, si bien en esos años se incrementó el aporte productivo de la mujer campesina a la familia, ella "siempre ha participado de la producción" (Campaña, 1982: 9). Por lo tanto, la sola ocurrencia de determinados procesos sociales no es condición suficiente para que éstos se conviertan en objeto preferente de la investigación científica y atraigan la atención del conjunto de la sociedad. El giro cualitativo de las ciencias sociales, el otro factor señalado, tampoco basta por sí solo para explicar la preocupación por la problemática de la mujer, aunque es indudable que el desarrollo de estas disciplinas ha contribuido con muchas herramientas metodológicas de análisis de esta realidad.

Existe un tercer factor cuya dilucidación es necesaria para explicar este "encuentro" entre testimonio y mujer. Consiste en el desarrollo de la conciencia crítica sobre la condición de la mujer en nuestra sociedad y sobre las relaciones e identidades de género. Se trata de un fenómeno complejo que ha alcanzado un gran desarrollo desde hace varios años, y que se expresa en diversas iniciativas y prácticas, creación de movimientos de mujeres y en líneas de investigación. ${ }^{17}$

En cste último caso, me refiero sobre todo a los estudios de la mujer y los estudios de género. 
Este interés cognoscitivo es explicitado por las diversas investigadoras. Escribe, por ejemplo, Kirai de León (1986: 12): "como profesionales optamos por dedicarnos a la problemática de la mujer por considerar que la subordinación es común a todas nosotras pero, además, en el trabajo concreto que realizamos, es nuestra propia experiencia de subordinación la que nos da, la más de las veces, las intuiciones y respuestas que perseguimos. De un modo complejo al analizar la vida de otras nos remitimos a los instrumentos y al compromiso que elaboramos como respuesta a una ideología que nos determina, a nosotras y a las protagonistas de este texto".

Por último, no podríamos dejar de mencionar el hecho que este interés por los testimonios, tiene en el caso de las mujeres, relación con el rescate que muchas investigadoras están haciendo de la literatura femenina. Ello ha incentivado la recuperación de obras de escritoras coloniales, la mayor parte de las cuales no fueron publicadas ni difundidas en la época en que se escribieron (Granillo, 1989). Pero también ha estimulado la producción de nuevas obras, algunas de las cuales se han transformado en clásicos de este género, como la autobiografía de Rigoberta Menchú (Burgos, 1983), de Domitila y otras (Logan, 1997).

\section{Sobre las condiciones de producción de los tes- timonios}

Ahora analizaremos las condiciones de producción de los testimonios, específicamente la "situación de entrevista" (Piña, 1988) y la "composición" de los relatos (Randall, 1983). La explicitación de estos dos elementos nos permitirá mostrar que el testimonio no es un reflejo espontáneo de las representaciones populares, sino más bien un producto común entre el investigador y el sujeto estudiado. ${ }^{18}$

Llamaremos "testimonio" al relato en que "un sujeto comunica a otro su experiencia" (Canales et al, 1987: 25). Es un tipo de relato en el que "un testigo habla para contestar a un interlocutor implícito" (Franco, 1988: 90) - o también explícito lo que, en todo caso, "supone una distancia y un diálogo desde posiciones diferentes - intelectual/ activista, extranjera/indígena, escritura/oralidad" (Ibid: 90). Aquí nos limitaremos a aquellas narra- ciones en cuya recolección o edición interviene un investigador social, descartando las producidas y recepcionadas de manera autónoma al interior de un grupo social.

De acuerdo con estos criterios, quedan fuera de nuestro alcance las historias de vida. Esto porque en ellas se investiga "el recorrido biográfico de uno o varios sujetos para lo cual se utiliza gran cantidad y diversidad de materiales (archivos, relatos indirectos, cartas, reconstrucciones históricas, contratos, etc.)" sin incluir necesariamente la autobiografía o relato de vida del o los sujetos en estudio (Piña, 1988: 4). El relato de vida, en cambio, es aquel "relato que hace el propio sujeto sobre sí mismo" y queda comprendido en nuestro análisis (Ibid: 4). Incluimos también un tipo de narraciones que podríamos llamar "tópicas" (Gluck, 1977), o temáticas, en las que el eje de la narración es uno o determinados sucesos de los que el narrador ha sido testigo y que se refieren a su entorno o medio social y no necesariamente a "su propia evolución a través del tiempo" (Piña, 1988: 5).

Piña (1999: 76) afirma, con razón, que "el hablante que genera el discurso autobiográfico, y sobre la vida del cuil el texto supuestamente se refiere, no es su único autor; usualmente otros intervienen en su elaboración, convirtiéndose en coautores a través del rol de interlocutor, entrevistador, editor, analista, etc." Y añade que "estas intervenciones alcanzan el estatus de coautoría". Sin embargo, no analiza las condiciones de esta "coautoría" ni si ella ponc en cuestión o no el carácter supuestamente espontáneo y directo del relato autobiográfico, que es lo que aquí pretendemos problematizar. Por otro lado, nos parece cuestionable la separación l'adical que establece en éste y otros trabajos (Piña, 1988 y 1990/1991) entre la expericncia biográfica, la vida del narrador, y su elaboracion narrativa, el relato autobiográfico. El sentido, podría decirse con Gadamer (1960), es siempre una relación, en la que el sujeto se apropia de experiencias pasadas, las interpreta y las toma como referencia al futuro. Lo que hace al relato autobiográfico una construcción de sentido no es cl que no represente la totalidad infinita que es cada vida individual (notése además el individualismo metodológico latente), como suponc Piña, sino precisamente porque a través de él se produce el vínculo entre experiencia y situación actual. Y esa construcción, para decirlo con la fenomenología, es siempre intencional, tiene un objeto: la propia experiencia, por múltiple, diversit e incluso inaprensible que pueda llegar a ser. 
Quienes utilizan los testimonios tienden a creer que éstos son una expresión directa y no mediada de las representaciones y modos de sentir y pensar del pueblo, sus mujeres, etc. Se emplea a menudo una metáfora para ilustrar esta tesis: la voz del pueblo. ${ }^{19}$ Dice Margaret Randall (1983: 7): "la voz (del pueblo J.I.V.) es de suma importancia: el testimonio es la transmisión de esa voz". Partiendo de consideraciones muy similares a éstas, Ore y Rochabrun (1987: 12) afirman que el investigador debe "dejar en suspenso sus propias categorías, hipótesis y prejuicios" para dar paso a las de las personas que estudia. Estos autores 1legan, así, a cuestionar la razón de ser de las ciencias sociales "¿por qué pensar que una explicación sociológica sería mejor que las de los protagonistas?" (Ibid: 12). Randall, en cambio, sostiene una versión bastante matizada de esta tesis. Plantea una coincidencia entre la "verdadera" historia y la historia contada desde las clases dominadas, que corrige, según ella, las deformaciones de la historia escrita desde las clases dominantes (Randall, 1983: 6-9).

Las afirmaciones anteriores contienen, a nuestro juicio, algunos elementos de verdad. Como señala Sergio Martinic (1986: 12): "los conocimientos que contribuyen a comprender y explicar los hechos tienen una dimensión de poder a través de la cual los grupos sociales disputan sus maneras de interpretar y fijar los límites de lo real, posible, o en otras palabras, de lo legítimo y normal". Tal es el caso del patriarcado que supone "un conocimiento oficial construido desde una perspectiva masculina (que) ... deja a la mujer fuera de muchas dimensiones de la vida social" (Ibid: 13). Podría resultar sugerente una perspectiva de investigación que recoja las interpretaciones de aquellos grupos sociales habitualmente no considerados en la investigación histórica y científicosocial de corte tradicional: indígenas, mujeres, pobladores, etc; el "saber popular" en los términos de Martinic.

Sin embargo, los planteamientos que estamos analizando van más allá de la propuesta de Martinic de constituir un campo de estudio del conocimiento y de las representaciones de los sectores populares. No pretenden tampoco, como Schutz y la escuela fenomenológica en sociología, estudiar el "sentido común" y la "construcción social de la realidad". Para Randall y los demás autores de esta línea, se trata de reducir el papel del investigador social a ser un "transmisor" (Lewis 1959), de las representaciones de los sectores populares expresadas en el testimonio. ${ }^{20}$ Ello debería implicar el abandono de toda forma de cuestionamiento acerca de la validez de dichas representaciones, ya que supondría el uso de categorías externas a los sujetos. A esto corresponde además una práctica
No ignoro que esta expresión se utiliza frecuentemente en otros contextos, por ejemplo, en la actividad política. El senador Beltrán Urenda criticó en 1992 a "algunas cúpulas de la metrópolis", a las que "[n]o les importa para sus fines la voz del pueblo ni la conveniencia nacional" (Urenda, 1992: 3). Desde el otro extremo del espectro político, el dirigente Martín Hernández (1991: 3 ) apelaba a "[l]a necesidad política de una fuerza de los $\sin$ voz gritando, haciéndose presentes directamente". Creo importante señalar que en este caso estamos frente al problema de la apelación al "pueblo" como forma de legitimación del discurso político, y no ante la cuestión de las condiciones de producción del testimonio en literatura y ciencias sociales. Las críticas que se hacen en este trabajo pretenden tener aplicación únicamente en este último ámbito. Por esta razón se deja también fuera de consideración la dimensión filosófica y religiosa del testimonio, abordada por Ricoeur (1983).
20 Debe advertirse que Lewis nunca excluyó las tareas investigativas, como han hecho algunos partidarios del testimonio. Además, la metodología utilizada en sus investigaciones combinaba métodos de tipo objetivo, como selección de poblados pobres según niveles de ingreso y de tipos de familias dentro de ellos, con otros subjetivos, como entrevistas y observación etnográfica (véase, especialmente, Lewis, 1959). Lamentablemente. Lewis no incorporó en el análisis estos dos tipos de aproximación, prefiriendo una presentación descriptiva de la vida familiar en un día típico bajo la premisa de lo que llamó "realismo etnográfico" en analogía con el "realismo literario" (Ibid: 19), que, sin embargo, abandonó en sus últimos estudios. La débil argumentación teórica sobre el concepto de "cultura de la pobreza" (Lewis, 1982) contribuyó a esto. 
investigativa que se agota en la recolección, edición y publicación de los testimonios, sin pasar a una interpretación o análisis propiamente dichos. ${ }^{21}$

Por otro lado, se busca relevar el rol del investigador como activista social, confundiéndose la utilización de testimonios en la investigación social y en una determinada práctica social. Respecto a lo segundo, es indudable que los testimonios pueden servir como instrumentos educativos o formadores. Se ha comprobado, por ejemplo, que el relatar sus experiencias les ha servido como herramienta terapéutica a personas afectadas por experiencias políticas traumáticas (Lira y Weinstein, 1984). Los testimonios se han utilizado como material educativo en la conformación de talleres de mujeres campesinas (Valdés, 1987). También se han señalado sus aportes en la docencia universitaria (Burgos y Díaz-Arroyo, 1985). Asimismo, puede destacarse su importancia como fuente de información respecto a muchas situaciones atentatorias a los derechos humanos ocurridas durante el régimen militar chileno. ${ }^{22}$ Estos cuatro casos revelan situaciones en las cuales el recolectar y publicar testimonios ha desempeñado un papel positivo en una determinada forma de práctica social. Sin embargo, pensamos que ello no puede implicar el abandono de objetivos de conocimiento por parte del investigador, incluso si dicho conocimiento pretende ser crítico de la sociedad existente. La distinción entre saber y poder puede ser relativizada, pero su identificación tiene gravosas consecuencias para la investi-

Refiriéndose a la historia oral en América Latina. dice Schwarzstein (1995: 47): "Muchas de estas experiencias están marcadas por un fuerte empirismo. Parecen sugerir que el historiador se diluye convirtiéndose en un mero recolector de los testimonios. En esta producción se observa un notable apego a la descripción de hechos aislados, la ausencia de planteos problemáticos y la predilección por la mera transcripción de la entrevista. Incluso, en algunos de estos trabajos se expresa el temor al posible efecto paralizante de los debates metodológicos...Por otra parte, en su accionar se plantean no sólo la recuperación de la memoria colectiva sino también la función social de la historia, proponiendo cambiar los lugares desde donde se habla y un saber no académico sino colectivo". gación científica y para la misma práctica política.

En segundo lugar, resulta cuestionable la suposición de que el testimonio es el lugar donde se expresan los dominados, suposición que está implícita en las tesis de Randall y de Ore y Rochabrun. "Hacer hablar al subalterno - escribe Jean Franco- ha sido históricamente una estrategia mediante la cual el saber se usa para asentar el poder" (Franco, 1988: 90). Franco menciona el caso de la novela latinoamericana post-colonial, un género basado en la exclusión de "los géneros de discurso orales" considerados expresión de "barbarie" (Ibid: 93). En estas obras, "la búsqueda de identidad personal y nacional siempre es encarnada por un personaje masculino y muchas veces intelectual. Así, la novela se asocia con el patriarcado, la subalternidad con la oralidad" (Ibid: 93).

El ejemplo más claro del fenómeno anterior lo constituiría, según Franco, el estudio de Oscar Lewis, Los hijos de Sánchez. Franco recuerda la afirmación de Lewis al comienzo de esta obra de que en ella "por primera vez habla el subalterno latinoamericano. Pero - se pregunta Franco ¿quién habla realmente? Lewis suprime sus propias preguntas y se representa sólo como un transmisor, aunque el libro está cuidadosamente estructurado según los ritos de pasaje antropológicos. Lo que garantiza la autenticidad de la narración es realmente "la voz" que se supone precisamente sin mediatización. Sin embargo, esta autenticidad es subvertida no sólo por el proceso de editar las grabaciones, sino - en el caso de una de las hijas de Sánchez, Consuelo - por el hecho que ella escribía su propia autobiografía y contribuía con ensayos escritos, que luego Lewis incorporaba al texto sin señalar su carácter escritutario" (Ibid: 93, destacados míos). ${ }^{23}$

En tercer lugar, es difícil aceptar que el testimonio sea un reflejo espontáneo de las representaciones de los sujetos. El modo habitual, aunque no único, de recoger las narraciones es la entre-

Pese a esta crítica, considero que la obra de Lewis ha hecho valiosas contribuciones al conocimiento de las expresiones culturales ligadas a la pobreza urbana latinoamericana, en especial por la metodología empleada en sus estudios, a la que me he referido en la nota 20 . 
vista, en la cual la intervención del investigadorentrevistador es decisiva. Este selecciona las preguntas y, como se sabe, ellas condicionan las respuestas. La entrevista es un proceso de interacción social en el cual hay un ajuste mutuo de intereses y expectativas entre el entrevistador y el entrevistado. "Podemos definir el proceso de narración como una actuación, donde el observador-registrador representa el papel menos activo - aún cuando impulsa y le imprime cierta dirección a quien narra - y es el destinatario del resultado de la interacción" escribe Kirai de León (1986: 13).

Si la narración del testimonio no estuviera mediada por esta intervención del investigador permanecería inalterada frente a distintos investigadores. Pero, como ha sido demostrado muchas veces, las características físicas, las preguntas y gestos de los entrevistadores influyen sobre las respuestas de los sujetos entrevistados. Por tanto, es posible suponer que una misma persona no hará exactamente el mismo relato ante dos entrevistadores distintos, lo cual no significa que su testimonio no sea confiable. ${ }^{24}$ La objetividad de la entrevista y, así también, la fídelidad del testimonio, no puede consistir en la anulación del investigador-entrevistador. Reside, en cambio, en la definición de parte de éste último de la situación en que se dio la entrevista, en la explicitación de las expectativas en juego y en el registro de los gestos no verbales del entrevistado en la medida de lo posible (De León, 1986; Gluck, 1977). ${ }^{25}$ Por último, no menos importante es conservar las preguntas hechas por el entrevistador en la edición de los testimonios (Portelli, 1987). Como intentaremos mostrar al final del trabajo, esto tiene que ver no sólo con una cuestión metodológica, sino también con un problema epistemológico respecto al carácter de la relación entre el investigador y los sujetos con los cuales lleva a cabo su estudio.

En cuarto lugar, la proposición que los testimonios son la expresión directa de las voces del pueblo deja sin explicar la producción específica de los testimonios para su edición. Es posible que esta composición de los textos refute tal tesis. Es el caso de la metodología propuesta por Margaret Randall. que ella emplea en sus propios trabajos. En una oportunidad, suprimió "toda referencia a preguntas nuestras, incluso nuestra presencia como transmisores de esa voz" (Randall, 1983: 33). En otra ocasión, empleó la siguiente técnica para montar un libro de testimonios: "apartamos los muebles de una habitación y nos pusimos en el suelo con montones de páginas de un testimonio tomado durante varios meses de trabajo. Colocamos las pilas de páginas según fechas aproximadas y, asimismo, con unas tijeras dimos forma a nuestro libro. Donde el informante se había acordado de algún hecho pasado, mientras relataba la vida de varios años más tarde, nosotros con tijeras trasladamos los momentos desarraigados a su tiempo real" (Ibid: 33).

La contradicción resulta evidente. Randall se define como una "transmisora" de la "voz" del pueblo, pero su papel va más allá de esto. Ella no duda en intervenir en la edición de los testimonios. Así, llega incluso a sugerir que deben eliminarse las reiteraciones de "ciertos sonidos o palabras muletas" para "dar una coherencia sintáctica al testimonio" (Ibid: 34 ). No se entiende porque éste no
Sigo aquí la distinción entre contiablidad y validez: en relación a los testimonios, la confiabilidad tiene que ver con la coherencia interna del relato, mientras la validez se refiere al contenido de verdad que puede establecerse respecto a los hechos relatados, aunque un testimonio no válido puede ser también muy importante como mostró Salamone (1977) respecto al "informante mentiroso". Sobre esta distinción en historia oral, véase: Hoffman (1974). entrevistas. Altamirano (1994: 69) ha planteado la diferencia cntre "la entrevista temática", que "busca únicamente obtener información sobre tópicos muy concretos de la experiencia humana y relega otros aspectos que no están directamente relacionados con és-

tos", y "Ja entrevista biográfica o las historias de vida", donde al cientista social le interesa conocer no sólo acontecimientos puntuales sino también "el contexto desde el cual éstos fueron vividos". Así descritit, y en relación con los testimonios, la distinción me parece poco clara o inexistente, pues en el primer tipo de entrevista no se puede prescindir de la visión o perspcctiva desde la cual el sujeto narra los hechos, por muy "objetivos" que éstos puedan ser. Desde mi punto de vista, la diferencia radicaría más bien en un cambio de ćnfasis, pero no en la exclusión o inclusión de la perspectiva del sujeto entrevistado. En el primer tipo de cntrevista éste sería el relato de hechos; en el segundo, todo $\mathrm{cl}$ recorrido biográlico de la persona. 
habría de poseer tal coherencia independientemente de las correcciones propuestas por Randall, pero, más que criticar a esta autora en particular, nos interesa discutir la validez de ciertas prácticas que son muy comunes en el trabajo con testimonios. ${ }^{26}$

Se objetará que algunas de las modificaciones propuestas por Randall son válidas, como también podrían serlo otras. No podemos más que decir algunas cuestiones muy generales sobre este problema que concierne a los especialistas. En primer lugar, debiera indicarse al comienzo de la publicación qué modificaciones se han hecho y por qué. En segundo lugar, deberían conservarse las preguntas de los entrevistadores, pues, como dice Portelli, "[...]cuando se excluye la voz del investigador se distorsiona la voz del informante" (Portelli, 1987: 44). Por último, sería necesario que antes de intervenir en los relatos se determinen los significados que puedan tener ciertas formas de expresión, palabras y reiteraciones. De este modo no se perderían elementos de sentido presentes en las narraciones. Estas consideraciones se aplican de manera distinta según el tipo de estudio que se esté realizando: una reconstrucción de hechos históricos, un estudio de mentalidades, publicación de autobiografías, entre otros.

Finalmente respecto a este punto, las consideraciones precedentes no agotan la discusión sobre el problema, ya que quedan sin analizar otros aspectos menores tales como la contextualización del testimonio, la preparación de las notas, titulación de los capítulos, etc. Ellos podrían ser objeto de un planteamiento crítico similar al que hemos realizado aquí.

A modo de confirmación de lo dicho, véase la siguiente descripción de la metodología utilizada por Acuña (1986: 9) en su estudio sobre Putaendo: "Durante 1985 se grabaron las entrevistas en el campo, pidiéndole a cada persona que contara su vida desde la infancia, haciendo algunas preguntas para profundizar en los temas más olvidados. Luego se transcribieron los cassettes - entre dos y cuatro por persona - en forma textual. Finalmente se trabajó en la composición de las historias; redactándolas de manera que resultaran legibles, pero conservando el lenguaje y espontaneidad de los relatos."

27 Rolf Foerster (comunicación verbal) me manifestó que esta fue una de las mayores dificultades que tuvo

\section{Conclusiones: hacia una investigación herme- neútica dialógica}

En las páginas anteriores hemos hecho un recorrido muy sintético por cuestiones relativamente amplias relativas a la producción y uso de testimonios en ciencias sociales. El análisis parecería conducir a una conclusión escéptica, similar a la que encontramos en algunos críticos literarios posmodernistas: la imposibilidad de representar al otro, en particular al dominado. Ciertamente, las dificultades que hemos indicado no son menores. Cuestionan radicalmente una forma de empirismo sociológico (o de las ciencias sociales en general), la creencia en una representación inmediata, directa del objeto de estudio, en este caso, de los sujetos populares a través del testimonio. Sin embargo, lo que se ha objetado es una cierta forma de interpretación del testimonio, no el testimonio en sí. Y esta concepción se trasluce en ciertas prácticas concretas como las que se han señalado. Es ideológica en el sentido francfortiano: falsa conciencia de una realidad, que, sin embargo, muestra también sus contradicciones y virtualidades.

La superación del empirismo testimonial es un momento ineludible de la crítica inmanente del testimonio, pero que, en tanto inmanente, puede también mostrarnos sus posibilidades abiertas. Lo que aparece como representación monológica, el relato testimonial, se nos revela como un diálogo oculto. En efecto, se trata de un diálogo entre el investigador y los sujetos entrevistados, pero donde el primero ha borrado las huellas de su presencia en el relato: sus preguntas, la situación de entrevista, la composición y edición de los testimonios. Por ende, no se trata de un diálogo completamente efectivo: uno de los participantes ha mantenido o pretendido mantener el control de la producción discursiva (oral y en algunos casos escrita). Aunque no siempre con pleno éxito, pues se dan casos en los que el entrevistado concientemente oculta ciertos aspectos de su vida o de la de su grupo, como también el de personas cuya trayectoria ha sido pública y que tienen un cierto relato bastante formado de su vida y lo transmiten al investigador, que debe emplear mucho talento para lograr penetrar más allá de esta narración estructurada. ${ }^{27}$ Como ejemplo de la primera situación, es bastante notable la afirmación de 
Rigoberta Menchú (Menchú, 1983: 271 cit.por Yúdice, 1992: 213) ${ }^{28}$ : "Claro, en toda mi narración yo creo que doy una imagen de [mi pueblo]. Pero, sin embargo, todavía sigo ocultando mi identidad como indígena. Sigo ocultando lo que yo considero que nadie sabe, ni siquiera un antropólogo, ni un intelectual, por más que tenga muchos libros, no saben distinguir todos nuestros secretos".

Los estudios del historiador Carlo Ginzburg (1992: 106-107) sobre la inquisición han mostrado que aún, bajo las condiciones de interrogatorio impuestas por los inquisidores, los relatos de los sospechosos contienen elementos de autenticidad que es posible rescatar a través del análisis contextual e histórico. Se trata de "textos intrínsicamente dialógicos", ya sea manera explícita --la serie de preguntas y respuestas propias de un proceso inquisitorial -- o implícita --como cuando los inquisidores deben aclarar la naturaleza de creencias sobre las que no tienen conocimiento previo. Los testimonios son el resultado de una comunicación social "profundamente desigual" pero susceptible de un desciframiento que nos revele, como en el caso de los Benandanti de Friuli (Ginzburg, 1966), un "estrato cultural profundo, del todo extraño a la cultura de los inquisidores" (Ginzburg, 1992: 107-108). Esta "falta de comunicación en el plano cultural entre jueces y acusados permitía, paradojalmente, el

para hacer la historia de vida del dirigente mapuche Martín Painemal Huenchual (Foerster, 1983). Un intento menos logrado es el de Sonia Sotomayor Cantero. cuya tesis de magister (inédita) sobre José Santos Millao (Cantero, 1995), se atiene casi literalmente al propio relato de vida de Santos. Fue este tipo de problemas el que llevaron a Nevins y colaboradores a orientar la historia oral desde los personajes públicos a los sujetos más anónimos.

28 Sorprendentemente, Yúdice interpreta esta frase como expresión de "la irreducibilidad" de "la experiencia estética", pero se trata, creo, de algo diferente. No es que Menchú diga que no puede recoger la experiencia de todo su pueblo en un relato (aunque éste es, sin duda el caso), sino que ella no está dispuesta a contárselo todo a un extraño, a revelar sus "secretos". Aquí hay un problema de limitación consciente de la narración (frente a terceros).

29 Una interesante propuesta en este sentido, está desarrollada por Batallán y García (1994), a quienes hago expresa mi deuda. Su trabajo me sugirió la idea de una producción participativa del conocimiento antropológico, aunque cllos no la orientan a los testimonios. surgimiento de un verdadero diálogo -- en el sentido de encuentro no resuelto de voces en conflicto, según propone Bakhtin" (Ibid: 111). De esta forma, en ningún caso podrá argüirse que el relato testimonial producido en la situación de entrevista no expresa, aunque de formas y grados diversos, la subjetividad del narrador, o sea, su visión y su manera de construir e interpretar discursivamente su experiencia. Pero, obviamente, el interrogatorio inquisitorial no puede ser el paradigma del testimonio.

Nos parece que podría explorarse la idea de diálogo desde una perspectiva hermeneútica que no excluya, sino más bien integre el análisis teórico externo y el uso de otras metodologías, aunque aquí no podemos tratar el problema de su articulación. ${ }^{29}$ Se trata de una posibilidad que hasta ahora se ha desarrollado de manera insuficiente dentro de las ciencias sociales. No desconocemos los riesgos ineludibles a ella, como la posible confusión entre objetivos de investigación y objetivos prácticos. Sin embargo, creemos que podría llegar a constituirse en una forma de producción e interpretación de los testimonios. No la planteamos tampoco como una forma excluyente de otras, pero, si nuestro argumento es plausible, cualquier propuesta relativa al testimonio debería abordar el problema central de la relación entre el investigador y el sujeto estudiado. ${ }^{30}$

30 En este punto, la visión comprensiva de las ciencias sociales, dentro de la cual incluyo la hermeneútica (no obstante las precisiones hechas por Gadamer (1967: 240; 1985: 17) respecto a que el objeto fundamental de su filosofía no era, como parecía derivarse de Verdad y Método, el proporcionar un fundamento nuevo a las "ciencias del espíritu". me parece excluyente de la concepción de Schutz (1953: 62-63) del cientista social como un "observador neutral", que "se separa de su situación biográfica dentro del mundo social" y se coloca en un "estar en una situación científica". Al menos en el caso del testimonio, no es posible hacer una separación completa entre estos dos planos, menos cuando el investigador realmente tiene que interactuar con las personas y grupos que estudia. Con ello no se quicre decir que no haya diferencia alguna entre participar en una comunidad y estudiarla, pero que no es posible pretender tampoco una distinción radical como sugiere Schutz. La idea de Habermas (1981: I, 167-171) del cientista social como un "participante virtual" me parece más apropiada. 
Como dice Gadamer (1960: 362), "[... Hla hermeneútica siempre se propuso como tarea restablecer un acuerdo alterado o inexistente". El testimonio podría verse como el resultado de un tipo de investigación hermeneútica dialógica, en el que ambos participantes, investigador y sujeto estudiado, deberían tener una participación lo más igualitaria posible en el establecimiento de las condiciones de entrevista, revisión y edición de los relatos. Esto no excluiría el análisis del relato de parte del investigador, pero se trataría de una autoreflexión sobre el proceso de producción del relato y sobre su propia precomprensión como intérprete activo. Una precomprensión sistemática que tomaría el lugar de la precomprensión teórico-práctica de los sujetos en la vida social, pero no se impondría por sobre ellas. ${ }^{31}$ Y no podría excluirse la autoreflexión del otro participante sobre ese mismo análisis. Ambos deberían ser considerados competentes en su capacidad de reflexionar críticamente sobre sí mismos y los demás, en lo que Gadamer llama "una conversación infinita, que se inicia una y otra vez y vuelve acallarse sin encontrar jamás un fin" (Gadamer, 1991: 151). Se trataría aquí de un relato a varias voces y modalidades, en el que se incluyeran, por ejemplo, la entrevista y las interpretaciones de ambos, entrevistador y entrevistado, o donde éste último podría al menos revisar el texto para su edición y aprobarlo.

De esta forma, el relato testimonial no sería algo transmitido directamente por el narrador ni impuesto por el estudioso, sino el resultado de esta relación. Esto, por cierto, no excluye el uso de material de entrevista desde una perspectiva externa. Sin embargo, cuando se trata realmente de abordar la subjetividad del sujeto popular, y no de reconstruir ciertos hitos históricos, o "datos" puntuales (aunque también en este caso valen las precauciones metodológicas que hemos señalado antes), parece más apropiado asumir con mayor radicalidad lo dialógico del testimonio como una forma de ciencia social que no sólo pretenda representar la subjetividad sino también incorporarla de manera activa en la propia práctica investigativa.

Se trataría, finalmente, de reconocer el carácter de sujetos de ambos partícipes en el diálogo. Al respecto, Sartre (1960: 49) hizo hace cuatro décadas algunos planteamientos clarificadores. Señaló como uno de los elementos de "confusión de las ciencias sociales", el que "el investigador se considera como referencia absoluta en relación con el interrogado, cuando el hecho que puedan hablar, corresponder, decirse cosas, y comprenderse viene que están en situación uno respecto al otro". El sociólogo o el antropólogo deben, por ello, situarse, reconocerse como miembros de una sociedad (que él definía algo estrechamente como "capitalista") y por tanto, reconocer su propia precomprensión previa a los sujetos que estudia. Por tanto no puede considerarlos tampoco como
31 Me baso aquí en la crítica de Habermas (1970) a Gadamer. Habermas plantea la necesidad de incorporar aspectos explicativos, elaborados teóricamente, a la comprensión hermeneútica, y propone a su vez una ciencia social crítica, que permita distinguir entre una tradición fundada en la coerción y otra fundada en un consenso verdadero. Considera el psicoanálisis como modelo de dicha ciencia social. Lamentablemente, como bien ha señalado Giddens (1976: 68), esta propuesta adolece de diversas dificultades, entre ellas, que la relación entre analista y paciente es "marcadamente oblicua e incluso autoritaria", donde "el análisis hermeneútico y el nomológico aparecen sólo bajo la forma de descubrimiento de motivos ocultos". Yo agregaría que la relación tiene una finalidad precisa, la curación del paciente, y se limita a ella. Los roles de analista y analizado son fijos. El mismo Gadamer (1971: 250) ha respondido a Habermas planteando que en dicha relación, el paciente y el médico "se ven envueltos y limitados a un determinado juego de roles sociales", lo que supone "un factor de perturbación en el trato social", entiéndase aquí en la praxis comunicativa cotidiana en la que el mismo psicoanalista participa. Y se plantea la cuestión inversa de la ubicación del psicoanalista y del psicoanálisis dentro de dicha praxis. Gadamer (1967: 241) se pregunta: "¿Qué relación guarda el saber del psicoanálisis con el puesto que ocupa dentro de la realidad social a la que él mismo pertenece?...La fuerzal emancipatoria de la reflexión que utiliza el psicoanalista encuentra sus límites en la conciencia social que él mismo, al igual que su paciente, comparte con todos los demás". Por cierto, yo entendería estos "límites" precisamente en el sentido que la capacidad emanciputoria que Habermas atribuye al psicoanálisis está circunscrita a condiciones muy distintas a las de la comunicación cotidianá. Por ende, es díficil considerar esto como base para un diálogo como cl que estoy señalando. La idea de Habermas de "racionalidad comunicativa" en el mundo de vida sí podría ser la base del mismo, como lo plantea el propic Habermas (véase el texto citado en la nota anterior). 
objetos: "Si se considera al hombre como un objeto que debe conocerse, y en consecuencia desconocido, es porque él mismo se refiere en relación al otro y en relación a sí mismo como desconocido" (Ibid: 51). Y la solución radica para Sartre en una "sociología de la situación" que exige también una "comprensión", lo que llamamos aquí una hermeneútica dialógica, aunque Sartre, a nuestro juicio apegado a una tradición anterior a Gadamer, la relacione con el movimiento de "interiorización". En todo caso, es un "conocimiento situado", en el que la distinción subjetivo-objetivo pierde vigencia. A diferencia de un proyecto teórico como el de Lévi-Strauss (1962: 357), para el cual "el fin último de las ciencias humanas no es constituir al hombre, sino disolverlo", Sartre plantea una vuelta al hombre, desde una antropología filosófica dialéctica. ${ }^{32}$

El instrumentario propuesto es hoy muy discutible. Lévi-Strauss apuntó correctamente la limitación de la antropología sartreana en cuanto ésta tiene como referencia una sociedad, la occidental
(Lévi-Strauss, 1962: 360-361). La hermeneútica que aquí proponemos plantea justamente el diálogo como una forma de aunar y vincular tradiciones y formas de vida diferentes, donde la diferencia principal, sujeto investigador/objeto investigado, pueda ser no anulada completamente, pero sí al menos puesta en cuestión en aras de una forma más participativa de investigación, para la cual el testimonio puede representar un modelo y a la vez una expresión significativa.

\section{Agradecimientos}

Agradezco a Antonia Santos, Marcelo Arnold, Rolf Foerster, Fernando García, Oscar Galindo, Hans Gundermann, Aldo Mascareño, Sonia Montecino, Carlos Piña y Jorge Vergara Estévez por su colaboración, críticas y sugerencias al trabajo. De los posibles errores soy, obviamente, el único responsable. Hago extensivos mis agradecimientos a Ximena Jiles y Sara Mac Fall por la traducción del resumen al inglés . pecto, vale la pena releer las notables reflexiones de Ricouer (1969, sobre todo: 33-70) respecto a la relación entre estructuralismo y hermeneútica. Sin embargo, debe notarse, como ha señalado Honneth (1990), la existencia de un espíritu romántico de origen rousseauniano en Lévi-Strauss, que no encuentra expresión teórica en la terminología estructuralista. Esto lo aproximaría, en mi opinión, a una concepción humanista de las ciencias sociales como la de Sartre, no obstante sus muchas divergencias con él. 


\section{BIBLJOGRAFIA ${ }^{33}$}

ACEVES, J.

1993

(Comp.). Historia oral, Instituto Mora Universidad Autónoma Metropolitana. México.

ACUÑA, L. 1986

ACUÑA, V.H. 1980

ADORNO, T. 1957

AHMED, A 1905

Hombres y mujeres en Putaendo: sus discursos y su visión de la historia. Biblioteca de la Mujer, Centro de Estudios de la Mujer (CEM), Santiago.

(Editor) Ilistoria oral e historias de vida, Flacso-Costa Rica, San José.

"Soziologie und empirische Forschung", en: Idem, Soriologische Schriften I (Gesammelte Schriften, Tomo 8), Sulukamp, Francfort del Meno, 1990, pp. 196-216. Traducción al español: "Sociología c investigación empírica", en: Adorno. Theodor et al, La disputa sobre el positivismo en la sociología alemana. Editorial Grijalbo, Barcelona, 1973, pp. 81-99.

"The politics of literary postcoloniality", en: Race \& Class $N^{\circ} 3$, enero-marzo. Londres, pp. 1-20.

ALTAMIRANO, G. Metodología y práctica de la entrevista, 1994 en: A AVV. La historia con micrófono. Instituto Moril, México, pp. 62-78.

BAL $A N$, J.et al Las historias de vida en ciencias so1974 ciales. Teoría y técnica. Ediciones Nucva Visión. Buenos Aires.

BATALLAN, G. y J. F. GARCÍA, Antropología y participa1994 ción. Contribución al debatc antropológico, cn: García. José Femando, La racionalidad en política y en ciencias sociales, Centro Editor de América LaLina, Buenos Aires, pp. 162-175.

BENAVIDES, L. Historia oral: problemas y perspec1984 tivas, Documento de Trabajo. Flacso, Santiago.

BENGOA, J. Ilistoria del pueblo mapuche. Siglos 1985 XIX y XX, Eds. Sur, Santiago, $2^{a}$ cdición 1987.
BÉRTAUX, D. "El enfoque biográfico: su validez me1980 todológicat. sus potencialidades". En Acuña, Victor Hugo (Editor), Ilistoria oral e historias de vida. Flacso-Costa Rica. San José. pp. 55-80. Ahora en: Proposiciones $\mathrm{N}^{\circ} 29,1999$, Eds. Sur. Santiago. pp. 52-74.

BÉRTAUX. D. (Ed.) Biography and society, Sage 1981 Publications, Beverlly Hills-California

BÉRTAUX, D. y P. THOMPSON, (Eds). Between genera1993 tions. Family models, myths and memories (International yearbook of oral history and life stories, Vol. II), Oxford University Press, Nucva York.

BEVERLEY. J. "Introducción", en: La voz del otro. 1992 Testimonio, subalternidad y verdad narrativa. editado por John Beverley y Hugo Achugar, Lima-Pittsburgh, Latinoamericana Editores, pp. 7-18.

BEVERLEY, J. y ACHUGAR, H. La voz del otro. Testimo1992 nio, subalternidad y verdad narrativa, op. cil.

BOURDIEU, $P$. "La ilusión biográfica", $\mathrm{cn}$ : Mistoria y 1986 Fuente (Oral N², México, 1989, pp. 2733.

BRAVO, J.A. (Ed.). Memoria histórica y sujeto po1987 pular, Documento de Trabajo, Eco, Santiago.

BURGOS. E. Yo me llamo Rigol)erta Menchú y así 1983 me nació la conciencia, Argos Vergara. Barcelonia.

BURGOS. N. y A. DÍAZ-ROYO, "El género testimonial: 1985 aplicaciones en la docencia", en: Homines, Vol. 9, N¹-2. San Juan, Puerto Rico, pp. 40-44.

CAMPAÑA. P. I a organización de la mujer campe1982 sina: realidades y perspectivas. Documento de Trabajo, Grupo de Investigaciones Agrarias (GIA), Santiago.

1985 "Capacilación de lá mujer campesina y" desarrollo rural". en: Educación y desarrollo rural, editado por Carlos Amtmann y Jubel Moraga, Universidad Austral. Santiago, pp. 253-267.

CANALES, M. et al I a subjetividad popular. La religión 1987 de los sectores populares. El campo pentecostal, Documento de Trabajo. Servicio Evangélico para el Desarrollo (SEPADE). Santiago. 
CANALES, M. "Lo tecnológico en la visión de mundo 1988 campesino", cn: Berdegué, Julio y Nazif, Iván, Sistemas de producción campesinos, Grupo de Investigaciones Agrarias (GIA), Scric GIA/4, Sintiago.

CRUZ M. E. y R. RIVERA. Y los campos eran nuestros 1984 (2 tomos). Libros de Hoy Nos. 8 y 9 . Serie Testimonios, Santiago.

CHIRICO, M. M. "La producción narrativa en la situa1990/1991 ción de entrevista: algunos puntos de partida", en: Cuadernos del Claeh Año 15, $2^{2}$ Scric. N 53 , Montevideo, pp. 77 87.

$\begin{array}{cl}\begin{array}{c}\text { DE LEÓN. K. } \\ 1986\end{array} & \begin{array}{l}\text { Andar andando, CEM-Pehuén. San- } \\ \text { tiago. }\end{array} \\ \begin{array}{c}\text { FOERSTER, R. } \\ 1983\end{array} & \begin{array}{l}\text { Martín Painemal. Vida de un dirigen- } \\ \text { te mapuche, Grupo de Investigaciones } \\ \text { Agrarias (GIA), Santiago. }\end{array}\end{array}$

FRANCO, J. "Si me permiten hablar: la lucha por el 1988 poder interpretativo", cn: Casa de las Américas, Año XXIX, No 171, La Habana, pp. 88-94.

GADAMER, H.-G. Verdad y método, Editorial Sígueme, 1960 Salamanca, 1977. Original: Wahrheit und Methode, J.C.B. Mohr, Tübingen, $4^{\mathrm{a}}$ edición 1975.

1967 "Retórica, hermeneútica y crítica de la idcología", cn: Idem, Verdad y Método II, Ediciones Sígueme, Salamancal, 1992. pp. 225-239. Original: Wahrheit und Methode. Ergän-zungen Register, J.C.B. Mohr, Tübingen, 1986.

1971 "Réplica a Hermeneútica y crítica de la ideología ", en: Idem, Verdad y Método II, Ediciones Sígueme, Sal amanca, 1992, pp. 243-265.

1991 "La hermeneútica y ha escucla de Dillhey", cn: Idem, El giro hermeneútico. Eds. Catédra, Madrid, 1998, págs. 131152. Original: Hermeneutik im Rückblick, J.C.B. Molhr. Tübingen, 1995.

GIDDENS, A. Las nuevas reglas del método socioló1976 gico, Amorrortu, Buenos Aires, 1987. Original: New rules of sociological method: a positive critique of interpretative sociologies, Hutchinson y Co. Lid., Londres.

GINZBURG, C. Die Benandanti, Europäische Verlag1966 sanstalt. Hamburgo, 1993. Original: I benandanti, Giulio Eunadi cditore. Torno.
1992 "El inquisidor como antropólogo", en: Mapocho No31, ler semestre, Santiago, pp. 103-112.

GLUCK, Sh, "What's so special about women? 1977 Women's oral history", en: Oral History, editado por David K. Dunaway y Willa K. Baum, American Association for State and Local History (AASHL), Nasluville, 2a edición 1987, pp. 221-237.

GRANILLO, L. "La cuestión de las mujercs que supie1989 ron latín”, en: Sociológica N $N^{\circ} 10$, año 4, México.

GUERRA. D. et al (Comps.) Las ñañas, sin editorial, Santia1999 go, 1999.

GUERRA, D. y J.C. SKEWES, "La historia de vida como 1999 contradiscurso: plicgues y repliegue de uni mujer", en: Proposiciones $\mathrm{N}^{\circ} 29$. Santiago, pp. 178-188.

HABERMAS, J. "La pretensión de universalidad de la 1970 hermencútica”, en: Idem, La lógica de las ciencias sociales. Tecnos, Madrid, 1988, pp. 277-306.

1981 Theorie des kommunikativen handelns (2 tomos), Suhrkamp Verlag. Francfort del Meno. Traducción al español: Teoría de la acción comuniativa. Taurus, Madrid, 1987.

HERNÁNDEZ, M. "Este es muestro tiempo" (Entrevista) 1991 en: Debate y Cambio $\mathrm{N}^{\circ} 6$, año IV, Santiago.

HOFFMAN, A. "Reliability and validity in oral history", 1974 en: Oral History, editado por D. K. Dunitway y W.K. Baum, op. cit, pp. 67. 73.

HONNETH. A. "Ein strukturalistischer Rousseau. Zur 1990 Anthropologie von Claude Lévi-Strauss" en: Idem, Die zerrisene Welt des Sozialen, Sulurkamp Verlag, Francfort del Meno, págs. 93-112.

HUGHES. E. "Introducción: el trabajo de cámpo en 1960 la ciencia social", cn: Junker, Bulford, Introducción a las ciencias sociales. EI trabajo de campo, Marymar, Bucnos Aires, 1972.

KAEMPFER. A. "Los prólogos testimoniales: paratexto, 2000 otredad y colonización textual" en:Estudios Filológicos $\mathrm{N}^{\circ} 35$. U. Austral de Chilc, Valdivia, pp. 191-206.

KANEFSKY. R. "Debunking a postmodern conception 1996 of history: a defence of humanist values of Joy Kogawa", en: Canadian Literature $N^{\circ} 148$, pp. $11-36$. 
LÉVI-STRAUSS, C. EI pensamiento salvaje, FCE, Méxi1962 co. 1964.

LEWLS, O. Antropología de la pobreza, FCE, Mé1959 xico, 1961 .

1982 "Cultura de la pobreza", en: Idem, Ensayos antropológicos, Grijalbo. México, 1986, págs. 107-120.

LIRA, E. y M. WEINSTEIN, "El testimonio de experiencias 1984 políticas traumáticas como instrumento terapćutico". en: Lira Elisabeth et al, Psicoterapia y represión política, Siglo XXI, México, pp. 17-36.

LOGAN, K. "Personal Testimony: Latin American 1997 Women telling their lives", en: Latin American Research Review, Vol. 32, $\mathrm{N}^{\circ} 1$. Alburquerque, New México, pp. 199-211

LORCA. M. y M. PINDA. María Pinda. Semblanza de una 2000 dirigenta indígena. Edición de los autores. Santiago.

MARCUSE, H. EI marxismo soviético, Alianza Edito1958 rial, Madrid, $3^{3}$ edición 1971.

MARTINIC, S. Saber popular, CIDE, Santiago, 2da. 1986 edición 1987.

MARX. K. "Einleitung", en: Grundrisse der Kri$1857 / 1858$ tik der politischen Oekonomie (MEGA, Tomo II/1.1), Dietz, Verlag, Berlín, 1976. págs. 17-45. Traducción al español: "Introducción general", en: Elementos fundamentales de la crítica de la economía política ( 2 Tomos), Tomo I, Ediciones Siglo XXI, Bucnos Aires. 1971, pp. 3-34.

MONTECINO, S. Las mujeres hablan: sector mapuche, 1982 urbano y rural. Documento de Trabajo, CEM, Santiago.

1984 Mujeres de la tierra, Ediciones CEM, Santiago.

1985 Historias de vida de mujeres mapuches, Documento de Trabajo, Serie Las Mujeres Hablan No 4, CEM. Santiago.

1996 "Devenir de una traslación: de la mujer al género o de lo universal a lo particular", cn: Montecino, Sonia y Rebolledo, Lorcto, Conceptos de género y desarrollo, Programa Interdisciplinario de Estudios de Género (PIEG), Serie $\wedge$ puntes Docentes, Universidad de Chile, Santiago, pp. 9-35.

MONTECINO, S.; REBOLLEDO, L. y A. WILSON. Diag1993 nóstico sobre inserción laboral de mu- jeres mapuches urbanas y rurales, Programa Interdisciplinario de Estudios de Género (PIEG), Serie Resultados de Investigación, Universidad de Chile, Santiago.

NÁRVAEZ, J. (Ed.) La invención de la memoria, 1988 Pchuén, Santiago.

NEVINS, A. "Oral history: how and why it was born. 1966 The uses of oral history", en: Oral History, cditado por David K. Dunaway y Willa K. Baum, op. cil, pp. 27-31.

ORE, M. T. y ROCHABRUN, G. "El desafío de la historia", 1987 en: Memoria histórica y sujeto popular, editado por Jorgc Andrés Bravo, Documento de Trabajo, ECO, Santiago, pp. 9-13.

PIÑA, C. 1986

"Sobre las historias de vida y su campo de validez en las ciencias sociales", en: Revista Paraguaya de Sociología, Año 23. Nº7, Asunción, pp. 143-162.

1988 La construcción del "sí-mismo" en el relato autobiográlico, Documento de Trabajo, FLACSO-Chile, Santiago.

1990/1991 "Sobrc la naturaleza del discurso biográfico", en: Cuadernos del Claeh Año 15, 2a Serie, No53, Montevideo, pp. 3963.

1999 "Tiempo y memoria. Sobre los artificios del relato autobiográfico", en: Proposiciones $N^{\circ} 29$, Santiago, pp. 75-79.

POLLOCK, M. "Paul F. Lazarsfeld, fundador de una 1979 multinacional científica", en: Wright Mills, C. et al, Materiales de sociología crítica, Las Ediciones de la Piqueta, Madrid, 1986, pp. 37-82. Original publicado en: Actes de la recherche en Sciences Sociales N ${ }^{2} 25,1979$, pp. 4560.

PORTELLI, A. "Las peculiaridades de la historia oral", 1987 en: Memoria histórica y sujeto popular, editado por Jorge Andrés Bravo, op. cit, pp. 35-46.

POUILLON. J. "Sartre y Lévi-Strauss. Análisis dialéc1964 tico de una relación dialéctico-analítica", en: Pingaud, Bernard et al, LéviStrauss. Estructuralismo y dialéctica. Paidós, Buenos Aires, sin fecha, pp. 103113.

RACZYNSKI. D. y C. SERRANO. Vivir la pobreza. Testi1985 monios de mujeres. Cieplán-Pispal. Santiago.

RANDALL, M. Testimonios, Alforja, San José, Costa 1983 Rica. 
RICOEUR, P. Hermeneútica y estructuralismo, Edi1969 ciones Megápolis, Buenos Aires, 1975. Original: Le conflit des interprétations, Editions du Scuil, París.

1983

"La hermeneútica del testimonio", en: Idem. Texto, testimonio y narración. Editorial Andrés Bello, Santiago, pp. 9 50 .

RINCÓN, C. "Vuelta del barroco y proliferación neo1994 barroca", en: De Orbis Hispani (2 Tomos), editado por Axel Schonberger y Klaus Zimmerman, Tomo 2, Domus Editoria Europaea, Francfort del Mcno. pp. 1779-1796.

RIVERA, S. y R. BARRAGÁN (Comps.) Debates Post-Co1997 Ioniales. Una introducción a los estudios de la subalternidad, Ed. HistoriasSephis-Aruwiyiri, La Paz.

SALAMONE, F. "The methodological significance of the 1977 lying informant", en: $\mathbf{A n t h r o p o l o g i c a l}$ Quarterly, Vol. 50, N³, pp. 117-124.

SÁNCHEZ-PARGA, J. La observación, la memoria y la 1989 palabra en la investigación social Centro Andino de Acción Popular, Qui10.

SARTRE, J. P. Sartre en Brasil. La Conferencia de 1960 Araracuara, Ed. La Oveja Negra, Bogotí.

SCHUTZ, A. "El sentido común y la interpretación 1953 científica de la acción humana", cn: Idem, El problema de la realidad social, Amorrortu Editores, Buenos Aires, $2^{\mathrm{a}}$ edición 1995. Original: Collected Papers: I. The problem of social reality, La Haya, Holanda, 1962.

SCHWARZSTEIN, D. "La historia oral en América Lati1995 na”, en: Historia y Fuente Oral N² México, pp. 39-50.

SOTOMAYOR C., S. Historia de vida de un líder mapuche 1995 Ms. evolué, Magister en Ciencias Sociales Aplicadas, Universidad de la Frontera. Temuco.

STARR, L. 1977

"Oral History", en: Oral History, editado por David K. Dunaway y Willa K. Baum, Op. Cit, pp. 3-26.

THOMPSON, P. The voice of the past. Oral history, 1978 Oxford University Press, Oxford, 3a reimpresión 1986. Traducción al español: La voz del pasado. Lahistoria oral. Ediciones Alfons, El Magnanim, Valencia, 1988.
TOLEDO, V. "Historia de las mujeres en Chile y la 1993 cucstión de género en la historia social" en: Huellas. Seminario Mujer y Antropología. editado por Sonia Montecino y María Elena Boisier, Centro de Estudios para el Desarrollo de la Mujer (CEDEM)-Facultad de Ciencias Sociales Universidad de Chile, Santiago, pp. $5 !-64$.

URENDA, B. "Alerta, regiones", en: (Diario) La Ter1992 cera. martes 3 de noviembre de 1992 , Santiago.

VALDES. T. 1988

VALDES, $X$. 1987

Venid, benditas de mi padre. Las pobladoras, sus rutinas y sus sueños. FLACSO, Santiago.

"Testimonios de mujeres en su dimensión educativa", en: Memoria histórica y sujeto popular, editado por Jorge Andrés Bravo, op.cit, pp. 53-59.

El papel de la mujer en la hacienda. Centro de Estudios de la Mujer (CEM), Santiago.

VALDES, $X$. ct al Historias testimoniales de mujeres 1983 del campo, Programa de Estudios de la Mujer Campesina e Indígena, Academia de Humanismo Cristiano, Santiago.

VALDÉS, X. y P. MATTA Oficios y trabajos de las mujeres 1986 de Pomaire, Cem-Pehuén, Santiago.

VANSINA, J. La tradición oral, Ed. Labor, Barcclo1967 na.

1985 Oral tradition as history. The University of Winconsin Press, Madison. Wisconsin.

VERGARA E., J. "Sociologías y antropologias de la vida 1995 colidiana", en: Perspectivas, Año I, N ${ }^{\circ}$ 2. Universidad Católica Blas Cañas, Santiago, pp. 44-54.

VILLALOBOS, S. "Deficiencias de la historiografía eu1993 ropea relativa a América. El caso de la frontera en Chile", en: Historia $\mathrm{N}^{\circ} 27$. Universidad Católica, Santiago, pp. 553566

WEYER, F. "Historia de vida de Luisa Caño", en: 1998 (Revista) Mazorka, Programa de Estudios e Investigaciones de Género, Santiago (disponible en página WEB del PIEG: www.uchile.cl. Universidad de Chile, Facultad de Ciencias Sociales. Programas)

YÚDICE, G. "Testimonio y concientización", en: La 1992 voz del otro. Testimonio, subalternidad y verdad narrativa. editado por John Beverley y Hugo Achugar, op. cit., pp. 207-227. 
